\title{
The Effects of Hosting Events on Destination Branding:
}

Dubai Expo 2020

${ }^{1}$ Sarthak Sharma, ${ }^{2}$ Ana Stranjančević, ${ }^{3}$ Daniel Marco-Stefan Kleber

${ }^{1,2,3}$ Academic Department of Business Administration

MU Dubai, UAE

16010007@modul.ac.ae

\begin{abstract}
This paper evaluates the effects of events on the destination brand of Dubai as it prepares to host the Expo 2020. The purpose of the study is to understand how large events impact development of a city's brand. Based on the results, conclusions can be made on whether the efforts for the Expo will have a lasting impact on Dubai's destination brand. The methodology acquires information about the effects of hosting events on Dubai's destination brand through the analysis of the Expo 2020. The Tourism Area Life Cycle (TALC) and other comparative models are utilized to understand correlations and applications to the Expo 2020. The paper considers the preliminary efforts of Dubai indicating the increased opportunities in the city and excitement in the global community. The results highlight that the successful initiation of Expo 2020 would display Dubai's capability of hosting events, differentiating it from other cities, and presenting a positive outlook for the economy. This study has been conducted before the official commencement of the Expo 2020 and therefore it gives a "before the event" perspective only. It could be improved by assessing the visitor interest and attitudes after the event and making cause and effect models to develop comprehensive conclusions about the impact. Expo 2020 has great importance to Dubai due to its economic and destination brand implications, confirming the uniqueness of the research.

Keywords: Dubai, Destination Branding, Events, Expo 2020, World Expo
\end{abstract}

JEL : M3

DOI : :10.24002/kinerja.v22i2.2390

Received : 08/01/2019 Reviewed: 08/16/2019 Final Version: 09/25/2019 


\section{INTRODUCTION}

Events are an opportunity for many nations to display their capabilities and economic progress. Major events, like the World Expo, are utilized by the authorities and businesses to make a lasting impression and boost destination brand. Destination branding, as a process of identifying the destination's strongest assets and using them in all marketing communications, significantly contributes to the promotion of the destination, in this case, the great Middle Eastern city of Dubai. Dubai has already transformed itself from a dessert to a bustling metropolis in an extremely short time. This necessitates the urgency to maintain the city's upward economic trajectory through new development and investment possibilities. Dubai will host the Expo 2020 focusing on key themes of connecting minds, creating the future and three sub-themes including opportunity, mobility, and sustainability (Expo 2020, n.d.). These themes are valuable in prolonging the city's brand, economic growth, and sustainability for years to come. The economic and cultural advancements that branch from hosting an event allow for the continuing transformation of the city (Bureau International des Expositions, n.d.). Expos are a crucial aspect of urban infrastructure systems, transforming the development of cities and having a long-term impact on its citizens.

The world economy is heading towards uncertain times and the need for sustainable development is receiving the utmost importance (The Associated Press, 2018). The world market is becoming increasingly saturated, and differentiation has become essential. For example, tourism makes a large part of Dubai's economy, however, other destinations are rising that may provide a similar experience to what Dubai has to offer. Singapore and Hong Kong are comparable examples of major tourist hubs that may have similar offerings to Dubai. Simply relying on mega construction projects to boost the city's brand is not the only approach. Dubai authorities continuously strive to adopt innovation to give the city an edge (Geronimo, 2018). It can be seen from their commitment to the Expo, technology and artificial intelligence, and sustainability.

This research aims to understand what impact Expo 2020 may have on Dubai's brand could enrich destination branding studies. This research will focus on and investigate three key areas through the analysis Dubai's destination brand such as the city's ability to differentiate itself through the Expo, its economic sustainability as one of the major themes of the Expo and its ability to retain a leading as a major tourism and investment hub.

\section{LITERATURE REVIEW}

\subsection{Destination Branding}


Destination branding is a process of identifying the destination's strongest assets and using them in all marketing communications. It can be developed in many ways, mainly through advertising, direct marketing, personal selling, public and media relations, a cooperation of media organizations, journalists, organizers, and film makers (Morgan \& Pritchard, 2004). Destination branding remains barely characterized to many experts in Destination Management Organizations (DMOs) and not prominent in tourism literature. (Blain, Levy, \& Ritchie (2005). However, increased attention is being given to destination branding especially in the digital age (Költringer \& Dickinger, 2015).

\subsection{Dubai's Destination Brand}

Studies suggest that Dubai's primary economic sectors, trading, tourism, and logistics, have a strong place in branding and image, and the city's overall success, mainly due to Dubai's geographical location (Hafeez et al., 2016). According to Hafeez, this also suggests that the success in these areas have a beneficial effect on the other sectors, such as construction and real estate. There is increasing competition among cities of the same nation, (e.g., Dubai competing with Abu Dhabi or Sharjah), therefore, branding becomes a way to differentiate a destination from its competitors, nationally and internationally (Souiden, Ladhari, and Chiadmi, 2017). Around, 200 economies worldwide are competing in the destination market, and Dubai is a successful example in various factors (Balakrishnan, 2009).

Dubai's Department of Tourism and Commerce Marketing (DTCM) is the primary authority for the city's tourism and branding (Dubai Government Portal, n.d.). According to DTCM, their vision is to make Dubai the leading destination for business, events, and travel and their mission focuses on attracting tourists and investment to the city. DTCM's work focuses on making Dubai a leader in tourism and business travel, raising the city's international standing for commercial activities, enhancing traveler's experience by providing innovative service and solutions, and promoting the tourism sector's economic contribution to develop the destination brand (Visit Dubai Portal, n.d.) This allows the Dubai to continuously attract new travelers and commercial investment and motivate them to return to the city.

\subsection{World Expo}

World Expos are large, global events organized and facilitated by governments to "educate the public, share innovation, promote progress and foster cooperation" (Bureau International des Expositions, n.d.). According to the official World Expo portal, these large events "showcase innovation and inspirational inventions to the society, and are today unrivalled among international events in their size, scale, length and visitor numbers". The quest for better living standards for all citizens is one of the core missions of Expos which is displayed through innovative answers to global challenges and best practices (Bureau International des Expositions, n.d.). 


\subsection{Dubai Expo 2020}

The Expo 2020 in Dubai is defined as the "festival of human ingenuity" and collaboration and partnership are important for new developments (Expo 2020, n.d.). According to the official Dubai Expo 2020 portal, millions are expected to visit Dubai for the expo with over two-hundred participants, and more than thirtythousand volunteers contributing. Additionally, the Dubai Expo 2020 brand usage and association will be exclusively available to proper commercial partners. The legacy of the Expo 2020 is greater economic development and exposure of Dubai (Oxborrow, 2017). In addition to the economy, infrastructure projects, such as the metro and pavilions, will boost the locations economic and tourism standing. Dubai will host the Expo 2020 with four key themes of Connecting Minds, Creating the Future, and sub-themes of Opportunity, Mobility, and Sustainability (Expo 2020, n.d.).

\subsection{The Effects of Hosting Events on Destination Branding}

Festivals and events, visitors, experiences and reactions of traders, all impact the branding of the destination in various ways (Upadhya, 2016). Tourists from around the world visit Dubai for events and festivals, primarily for business, shopping, networking, and other purposes. The Expo 2020 will "impact the entire demographics, economy, and infrastructure of Dubai" and this has made Dubai the tourism hub of the Middle East according Upadhya (2016). Community participation, and a suitable strategic and cultural fit with the destination is key (Jago et al., 2003). Additionally, it is important to note "the need for an event to be differentiated from others, the longevity/tradition of the event at the destination, cooperative planning between key players, media support, and the effects of events with the overall portfolio of events" (Jago et al., 2003). Events "contribute to destination awareness, perceived quality, brand associations, destination loyalty, and destination positioning" (Dimanche, 2002). While destination attractiveness, functionality, and ambience are important and "correlate with perceived quality", commercial criteria have greater value (Hankinson, 2005).

\section{METHODOLOGY}

The methodology that is used by the study has been selected to acquire accurate information and conclusions about the effects of hosting events on Dubai's destination brand, specifically through the analysis of development relating to the Expo 2020.

\subsection{Selection of Methodology}


In-depth interviews will be given utmost priority as the topic is associated with the effects of events on destination branding prior to the official event. The primary data will assist in providing relations between destination branding, events, and Expo 2020 to the city of Dubai. Additionally, emphasis would be given to individuals who have experience in relation to the themes of the Expo, which includes the main themes of Connecting Minds, Creating the Future, and subthemes of Opportunity, Mobility, and Sustainability (Expo 2020, n.d.). Officials or professionals who had some relation to a governmental organization such as tourism board, trade event hosts, and business owners could provide informative perspective on the topic.

The interview questions would try to obtain an understanding of what destination branding is in the interviewee's perspective. The questions will assess the importance of the upcoming Expo and its impact on the overall Dubai market. They will provide information on the relation between events and destination branding and how the Expo will apply it. Finally, the interview questions will give an indication on the differentiation the Expo will provide from Dubai's competitors.

In-depth interviews provide the best and most reliable perspective and information on this specific topic. Due to the fact Expo 2020 has not yet commenced, the use of survey questionnaires to gauge audience perspective would be inapplicable as the focus of the topic would make it challenging to obtain accurate information from the general audience. In-depth interviews will be given greater importance because the topic relates to the effects of events on destination branding prior to the official event. The primary data will help in providing connections to destination branding, events, and Expo 2020, and how it all relates to the city of Dubai.

The secondary data utilized in the research was obtained from verified journals, books, and online articles. There are limited studies on this specific or related topics of world expos. However, major events do have lasting impact on the local economy. For example, major sports events bring in investment and improvements in local infrastructure, along with advantages for the participants and the hosting community (Gratton, Shibli, \& Coleman, 2006). The parallels to the Expo 2020 may be similar with greater economic implications than sporting events. Most of the secondary sources define the key concepts in the research and relate it to the topic of destination branding. Secondary data is supplementary to the primary data and gives a foundation for many of the conclusions made in the paper.

\subsection{Research Instrument}

Along with primary and secondary data, use of models and comparisons are used to visualize the impact of Expo 2020. The primary model used is the tourism area life cycle model (TALC). The TALC model helps managers assess the evolution of a tourist destination and the implications of increased tourism development in an area (Butler, 2006). The model focuses on the visitor number 
through a time period which goes through different stages such as exploration, involvement, development, consolidation, and stagnation, rejuvenation, or decline. This model is applied to Dubai's brand and the tourism sector, and assumptions are made on what TALC elements the city is experiencing or will experience. The first phase is exploration where a new tourist offering is introduced. The second phase is involvement where visitor patterns start to emerge due to increased number of tourists. The third phase is development where investment and regulation are required to further advance the tourist destination. The fourth phase is the consolidation stage where the area is a major tourist destination and more players, both local and international, are involved. The stagnation phase is when there is a lack of growth or development in the tourism arena. The last phase including decline and rejuvenation, where either the tourist number decline or efforts such as promotion or investment revive the tourist sector. The TALC model can be utilized to give an indication of the economic health of Dubai and its longterm sustainability.

\subsection{Sampling Procedures}

Due to in-depth interviews being the primary format for the research, the sample would consist of industry professionals and experienced individuals. In research studies, the sample size of interviewees is most often determined by the point of data saturation (Guest, Bunce, \& Johnson, 2006). Data saturation refers to a particular point in a research where additional information will not enhance or change the conclusions of a study. There are differing opinions on establishing this due to possible variations in research or the preferences of author. The initial step would be to identify the least number of interviews required for preliminary analysis and developing a conclusion. Then, the number of additional interviews, that should be conducted before reaching the point of data saturation, need to be specified. Using this method, we can make judgement on the number of interviews conducted and the viability of those interviews.

Ideally, the sample size of the interviewees is six to seven individuals, with at least five providing accurate and usable information for the research. As the Expo 2020 is approaching, there is a positive outlook on what the event would bring to the destination brand of Dubai. The main aspect for the in-depth research is that the interviewees come from varying industries, but they have some relation to the Expo. This brings in different perspectives, however, their conclusion of positive impact of the Expo remains the same or, at least, similar. The interviews provide the basis for the research and give accurate insight into the primary and updated perspective on the case. These inputs give an insight on the impact of initial efforts and what is to come for Dubai's brand in the future.

\section{RESULT AND DISCUSSION}


The results of the discussion are obtained from in-depth interviews and are supported by models and comparisons. The interviewees included individuals who were industry and academic professionals. The main aspects that were considered in the research included the importance of destination branding and events, the current standing of Dubai's destination brand, and the economic implications for the city's future growth. The focus for the study is the analysis of the Dubai Expo 2020, which is being touted as a game changing event presenting new opportunities for the city. The research showcases the Expo's importance is deeper in terms of how Dubai, as a brand, will support the various industries that rely on the the city being a leading destination for tourism, investment, employment opportunities, event venue and trade. The conclusions made in the research confirm that the Expo 2020 will give a boost to Dubai's destination brand and economy even through the current global economic slowdown, and offerings from other major destinations.

\subsection{Results and Findings}

\subsubsection{Destination Branding and Events}

Destination branding showcases the characteristics of a destination and develops an image of experiences and services offered. Destination branding is part of destination marketing and focuses on adding value to a destination. There are many travelers or consumers that make decisions based on the image which indicates that sometimes the image receives greater importance than the actual characteristics. Thus, destination branding can provide greater opportunities through image development. However, there are challenges in the implementation of destination branding. There are different audiences with differing interests and capturing all the preferences could be difficult. Organizational and environmental structure could prevent brand strategy to influence how a destination operates and impede with its image. There must be a consensus to build a communication platform that focuses on fresh, bold, and imaginative ideas.

Events are a major part of destination branding as they bring in increased number of visitors. Additionally, events could shape the image of a destination and attract greater number of tourists. The cultural and regional importance of a country can be displayed, bringing down barriers and stereotypes of the destination. The economic advantage is brought by the financial and infrastructure investment that boosts the local business environment. There are sectors of the economy that reap the benefits, such as the real estate market located near the event location.

\subsubsection{Dubai's Destination Brand}

Dubai is a dynamic city that is always changing. The visionary leadership of Dubai and the United Arab Emirates is strong and development oriented. A major aspect of the city's brand is that it has a mix of cultural heritage and openness to new innovation and tolerance to diverse groups of people. Dubai is different because it provides a middle eastern touch and environment and has a different 
economic focus compared to other cities like Singapore. Singapore shares many similarities with Dubai, but presents a more Asian touch and a different industrial advantage.

The Expo 2020 is an opportunity for Dubai to display its true potential for continuous growth and development. However, it would be difficult to make definite prediction on whether Expo 2020 will have a lasting impact on the city. There will be long-term advantages through the infrastructure developments, and destination brand awareness. Experts, researchers, and destination marketing organizations (DMOs) can be utilized to avoid a decline stage after the Expo has ended. Nonetheless, the value brought from the Expo will provide growth to the existing markets, and impact other economies in the region. The themes of the Expo, which are connecting minds, creating the future, with the sub-themes of opportunity, mobility, and sustainability, reflect Dubai's goals. Dubai is a destination that connects the world, both geographically and economically. Many from around the globe come to the city bringing their skills and knowledge which relates to goals of the Expo.

The tourism market is an ideal sector to analyze as it relates to visitations during the event and may indicate the economic health of a city. There is a consensus that the Expo will give a boost to the tourism sector in Dubai, however, it is difficult to predict without assessing the exact calculations. Destination management organizations (DMOs) can develop studies assess the true impact and create efforts to ensure Dubai continually develops. Butler's tourism area life cycle model could be applied to Dubai's case.

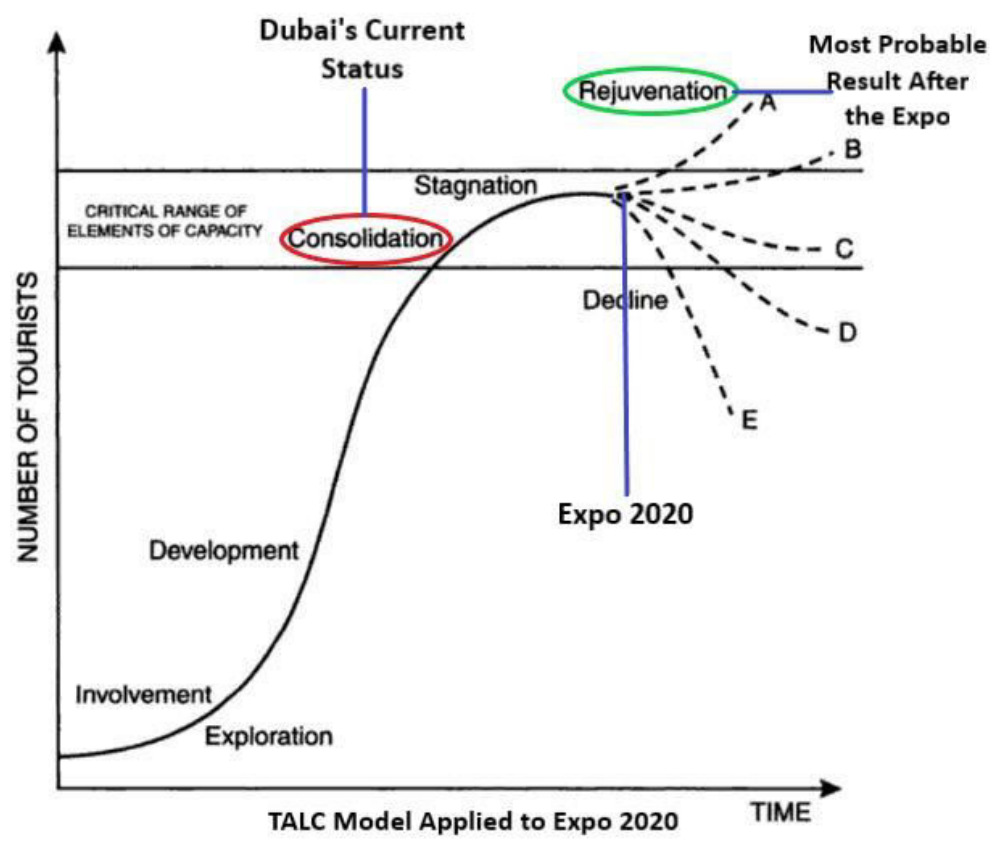

Figure 1. TALC Model Applied to Expo 2020 
There is indication that Dubai is currently in the consolidation phase. Tourism is a primary sector in the economy and the number of visitors to Dubai is still growing. During the time period of Expo, including the months before, during, and after the event, a rejuvenation scenario is most probable. The investment and contribution made to the successful initiation of the event is most likely to have a lasting impact on Dubai's image and economy. As long as the focus remains on growth and economic conditions are favorable, Dubai will maintain itself a tourist hub of the Middle East.

\subsubsection{Economic Implications and Future Growth}

Events bring in great destination branding advantage to a destination. However, there are other tools in the field of marketing that are comparable to events in bringing greater number of tourists. Dubai has identified stakeholders and utilized influencers that bring attention to the city's experiences. Dubai can also use image polishing by breaking barriers and presenting a unique image exclusive to the city. Different sectors of the economy, such as the hotel or cruise ship industry, could be assessed to understand the seasons and preferences of the visitors. Previously, Dubai presented itself as a luxury destination, however, more recently, low cost travelers are coming to the city through the increase in budget hotels and experiences. This is an advantage, but it may dissuade consumers who visit or view Dubai as a premium destination and a playground for the rich.

Destination branding brings in economic advantages that provide possibilities for sustainable economic development. Depending on a limited number of primary sectors is not ideal due to increased vulnerability. Expo 2020 and the promotion of Dubai's brand bring in social advantage to the city through increased diversity and opportunities, better economic prospects and diversification, and environmental sustainability through innovation and green initiatives. As Dubai has invested massively on innovating and advancing itself, it must become a pioneer and set example for other cities around the world. Through experimentation and best practice example, the city can implement new ideas and enhance its image.

As global economy is facing uncertainties, the degree of success of the Expo 2020 and its impact on Dubai's economy cannot be guaranteed. Major economies around the world have moved away from free trade towards domestic interests. The United Arab Emirates has remained fairly open with its economic partners and has been inviting to foreign investment. It becomes important that Dubai continues to maintain relationships with those its shares values and beliefs as well as developing new partnerships. The tactical long-term thinking would make the city's brand an inviting destination with greater economic freedom.

The outlook for the Expo 2020 is positive and the excitement is visible in the business community. The Expo strives to represent an image of Dubai that is developed, advanced, and welcoming. For many, it is more personal, as the Expo could provide opportunities for growth and employment. In any case, Dubai's destination brand will be represented and large number of visitors will come to 
Dubai. The image and experience that Dubai provides its visitors will have a lasting impact on the city's economy and destination brand.

\section{CONCLUSION}

The results in the research confirm that Expo 2020 will have a definite impact on Dubai's destination brand. The outlook is positive due to the investments and promotions made for the event. Not only will the Expo 2020 develop the city's image, but enhance different sectors of the economy. The impact of major events on a city's economic standing has been realized in prior studies, even though, the event may be different from the World Expo. It is apparent that there are connections between the brand of the city and events. The definitions and studies of the basic concepts presented in this thesis are largely available and they provide a foundation for the overall research. However, there was limited information on the pre-event process that produces significant economic activity and attracts many foreign players. This research could facilitate the gaps in the aforementioned area and bring in a new perspective on the impacts of activities prior to the event. Additionally, future studies may assess the post-event activities and develop comparative studies. Through literature analysis, the overall topic becomes absolutely relevant to understanding and applying the research to future events or processes.

The findings from this research could be used to assess the effects of events on the destination brand and what impact the Expo 2020 may have on Dubai. It could be used as a preliminary assessment before the official commencement of large-scale events to analyze the efforts made by the authorities and businesses, and the fruits of those efforts. The results from this paper could assist in avoiding pitfalls that destinations may make when developing their branding strategy. Based on this case, further studies could be done after the Expo to see the before and after relation. For example, this research gives a "before the event" perspective, and a new study could be conducted to see the difference and similarities in the predictions and efforts after the event, and also develop a cause-and-effect model. Overall, it is a crucial addition to the study of the relations between events and destination branding, and how it may impact the location where it is being hosted. For further extension of the study, it is possible to assess the interest and excitement of the audience before and after the Expo. This could help analyze if individuals are interested in coming to Dubai for the Expo, or understand how they view Dubai's brand and marketing before or after the actual event. Moreover, conclusions made in this paper could be compared with the actual impact on the destination brand of Dubai in 2020. 


\section{REFERENCE}

Blain, C., Levy, S. E., \& Ritchie, J. B. (2005). Destination branding: Insights and practices from destination management organizations. Journal of travel research, 43(4), 328-338.

Butler, R. (Ed.). (2006). The tourism area life cycle Vol. 1 (pp. 1-11). Channel view publications.

Dimanche, F. (2002). The contribution of special events to destination brand equity. In K. W. Wöber (Ed.) City Tourism 2002: Proceedings of European Cities Tourism's International Conference (pp. 73-80). Vienna: Springer.

Gratton, C., Shibli, S., \& Coleman, R. (2006). The economic impact of major sports events: a review of ten events in the UK. The Sociological Review, 54(2), 41-58

Guest, G., Bunce, A., \& Johnson, L. (2006). How many interviews are enough?: An experiment with data saturation and variability. Field Methods, 18, 59-82.

Hafeez, K., Foroudi, P., Dinnie, K., Nguyen, B., \& Parahoo, S. K. (2016). The role of place branding and image in the development of sectoral clusters: The case of Dubai. Journal of Brand Management, 23(4), 383-402

Hankinson, G. (2005). Destination brand images: A business tourism perspective. Journal of Services Marketing, 19(1), 24-32

Jago, L., Chalip, L., Brown, G., Mules, T., \& Ali, S. (2003). Building events into destination branding: Insights from experts. Event management, 8(1), 3-14

Költringer, C., \& Dickinger, A. (2015). Analyzing destination branding and image from online sources: A web content mining approach. Journal of Business Research, 68(9), 1836-1843

Lecardane, R., \& Zhuo, J. (2003). Great Event, A New Strategic Instrument for Urban Development: On the Impact of World EXPO on City and Society. Time Architecture, 4(3), 28-31

Lecardane, R., \& Zhuo, J. (2003). Great Event, A New Strategic Instrument for urban Development: On the impact of World Expo on City and Society.

Morgan, N., \& Pritchard, A. (2004). Meeting the destination branding challenge. Destination branding, 59-79 
Souiden, N., Ladhari, R., \& Chiadmi, N. E. (2017). Destination personality and destination image. Journal of Hospitality and Tourism Management, 32, 5470

Stephens Balakrishnan, M. (2009). Strategic branding of destinations: A framework. European Journal of Marketing, 43(5/6), 611-629

\section{External links:}

Department of Tourism and Commerce Marketing (DTCM), Dubai. (n.d.). Retrieved from https://www.visitdubai.com/en/department-of-tourism/about-dtcm

Expo $2020 \quad$ Themes. (n.d.). Retrieved from https://www.expo2020dubai.com/en/themes

Geronimo, A. (2018, November 13). Dubai to accelerate developments in technology, sustainability and Al. Retrieved from https://www.tahawultech.com/region/uae/dubai-to-accelerate-developmentsin-technology-sustainability-and-ai/

Government Departments. (n.d.). Retrieved from http://www.dubai.ae/en/Lists/GovernmentDepartments/DispForm.aspx?ID=7

Oates, G. (2015, September 10). Interview: Miami Tourism CEO Explains the Essence of Destination Branding. Retrieved from https://skift.com/2015/09/10/interview-miami-tourism-ceo-explains-theessence-of-destination-branding/

Oxborrow, I. (2017, August 08). Dubai Expo 2020: All you need to know. Retrieved from https://www.thenational.ae/uae/dubai-expo-2020-all-you-need-to-know$\underline{1.617 \overline{93}}$

The Bureau International de Exposition. (n.d.). Retrieved from https://www.bieparis.org/site/en/what-is-an-expo

The Associated Press (2018, November 21). World economy has 'passed its peak' and faces growing risks, OECD warns. Retrieved from https://business.financialpost.com/news/economy/world-economy-haspassed-its-peak-as-trade-wars-weigh

Upadhya, A. (2016, March 1). The Role of Events and Festivals in Destination Branding. Retrieved from https://www.skylineuniversity.ac.ae/research/roleof-events 
The Effects of Hosting Events on Destination Branding: Dubai Expo 2020

(Shartak Sharma, Ana Stranjančević, Daniel Marco-Stefan Kleber) 